\title{
Agronomic responses of Italian ryegrasses infected with different Neotyphodium strains
}

\author{
B.M. COOPER ${ }^{1}$, D.E. HUME ${ }^{2}$, K.A. PANCKHURST ${ }^{1}$ and A.J. POPAY ${ }^{3}$ \\ ${ }^{1}$ AgResearch, Kerikeri Research Centre, PO Box 23, Kerikeri 0245, New Zealand \\ ${ }^{2}$ AgResearch, Grasslands Research Centre, Private Bag 11008, Palmerston North 4442, New Zealand \\ ${ }^{3}$ AgResearch, Ruakura Research Centre, Private Bag 3123, Hamilton 3240, New Zealand
}

'bruce.cooper@agresearch.co.nz

\begin{abstract}
Italian (Lolium multiflorum) and short-term hybrid ryegrasses (L. boucheanum) are utilised by farmers for their reliable establishment and yield potential for winter feeding, but lack summer production and persistence. To improve the performance of these ryegrasses, endophyte (Neotyphodium lolii) strains from perennial ryegrass were inoculated into several cultivars and evaluated for agronomic performance in the Northland region of New Zealand. 'Moata' tetraploid Italian ryegrass families usually showed a reduction in yield when infected with the AR5 strain compared with endophyte-free Moata. Infection of the Italian ryegrass cultivars 'Corvette' and 'Status' with the $N$. lolii endophytes strains, AR1 and more particularly AR37, usually increased plant production and persistence. Natural infection with the $N$. occultans endophyte also improved plant performance. Improved plant performance was most closely associated with reduced damage from African black beetle. Interactions between plant line/cultivar and endophyte strain offer the potential for plant breeders to provide enhanced endophyte-infected cultivars of Italian ryegrasses to farmers.
\end{abstract}

Keywords: endophyte, Neotyphodium lolii, Neotyphodium occultans, Italian ryegrass, Lolium multiflorum, dry matter yields, plant persistence, insect damage

\section{Introduction}

Italian ryegrass (Lolium multiflorum) and short-term hybrid ryegrass (Lolium boucheanum) are utilised by farmers because of their good establishment and greater productivity compared to perennial ryegrass (Lolium perenne) during the autumn, winter and spring (Lancashire 1982). While these grasses are not expected to persist as well as perennial ryegrass, with adequate rainfall they will grow well into a second and subsequent year in New Zealand but are vulnerable to damage from insect pests such as Argentine stem weevil (ASW) (Listronotus bonariensis), and in the upper North Island, damage from African black beetle (Heteronychus arator).

Italian/hybrid ryegrasses in New Zealand are commonly infected with Neotyphodium occultans endophyte (Forde et al. 1988). Latch et al. (1988) and Prestidge (1991) postulated that this is a result of a selective advantage for infected plants, and may be dependent on the environment and age of the pasture (Hume et al. 1993). This endophyte provides protection of seedlings from Argentine stem weevil attack (Stewart 1985) but has unknown effects on other insects. Hybrid ryegrasses may also naturally host $N$. lolii ('wild-type' strain infecting ryegrass in New Zealand) which at least for populations from Northland imparts resistance to stem weevil attack similar to that

Figure 1 Mean of four herbage mass scores (1 to 6, 1 = low mass) of 49 'Moata' tetraploid annual ryegrass lines in rows at Kaikohe in 1991. "Control" is Moata free of endophyte, while all other 48 lines of Moata are infected with the AR5 N. lolii strain. Error bar is LSD, $\mathrm{P}<0.05$.

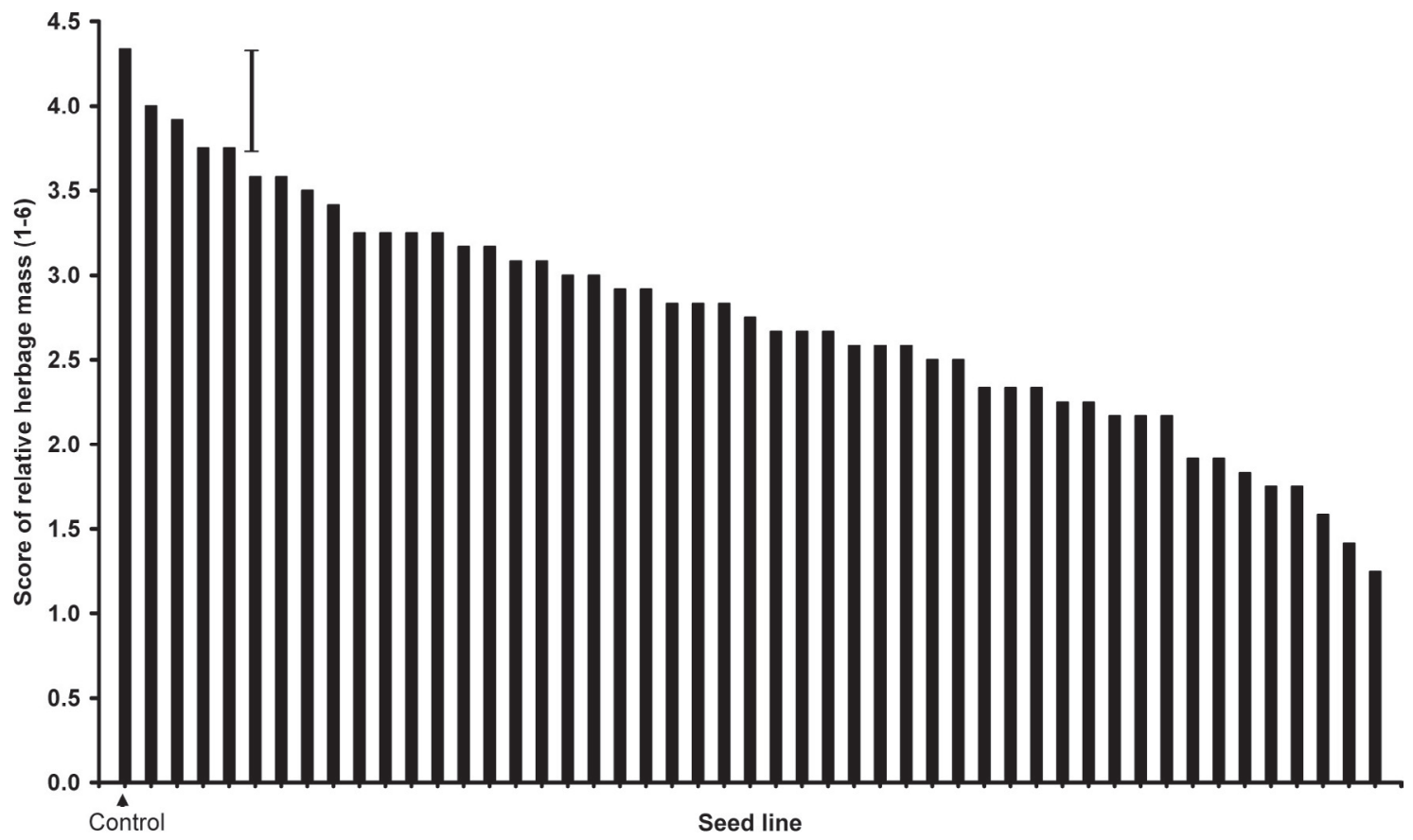


Table 1 Effect of endophyte species and strain on growth of Italian ryegrass at Kerikeri. Percent endophyte infection $(\% \mathrm{E})$ is the rate of viable endophyte infection in sown seed. Herbage mass score is a mean of 14 scores of ryegrass rows taken over 20 months. Ryegrass yields are total of 16 harvests over 2.5 years. Plant frequencies determined mid-autumn of Year 1 after black beetle damage in late summer (100 observations per plot).

\begin{tabular}{ccccccc}
\hline Cultivar & Endophyte & $\% \mathrm{E}$ & $\begin{array}{c}\text { Herbage mass } \\
\text { score }(1-10)^{\dagger}\end{array}$ & $\% \mathrm{E}$ & $\begin{array}{c}\text { Yields } \\
\text { (kg DM/ha) }\end{array}$ & $\begin{array}{c}\text { Plant } \\
\text { frequency }\end{array}$ \\
\hline Corvette & N.occultans-low/Nil & 10 & 6.5 & 0 & 18000 & 17 \\
& N.occultans-moderate & 50 & 7.0 & 76 & 24450 & 23 \\
& AR1 & 83 & 6.2 & 98 & 24500 & 22 \\
Status & AR37 & 70 & 7.1 & 93 & 26510 & 31 \\
& N.occultans-low & & & 15 & 18880 & 14 \\
LSD 5\% & AR1 & & & 87 & 21840 & 23 \\
\hline
\end{tabular}

$\dagger 1=$ low mass, $10=$ high mass

of perennial ryegrass infected with $N$. lolii (Piggot et al. 1988). Internationally, many naturalised populations of L. multiflorum have high levels of $N$. occultans infection suggesting that there is a selective advantage conferred by endophyte infection possibly through pest protection (de Battista 2005; Sugawara et al. 2006).

In New Zealand trials conducted at Palmerston North (lower North Island), 'Grasslands Moata' tetraploid Italian ryegrass infected with the AR6 endophyte strain from perennial ryegrass was compared to Moata plants without endophyte (Popay et al. 1995). AR6 in Moata was found to significantly reduce the incidence and severity of stem weevil larval damage but not to the same extent as for perennial ryegrass infected with AR6. This may be due to reduced concentrations of peramine, the main alkaloid responsible for stem weevil resistance, in tetraploids and Italian-hybrid types compared with perennial ryegrass, combined with differences in plant attractiveness factors (Stewart 1987; Popay et al. 2003). In contrast, more recent work in Northland (upper North Island) showed increased yields and persistence of the Italian ryegrasses 'Grasslands Status' and 'Corvette' infected with two $N$. lolii endophytes, AR1 and AR37, over the same cultivars with a low frequency of $N$. occultans infection or free of any Neotyphodium endophyte (Cooper et al. 2006).

This paper reports on three agronomic evaluations of Italian ryegrasses conducted in Northland where different endophyte strains resulted in a range of detrimental to positive effects on yield and persistence.

\section{Materials and Methods}

\section{Tetraploid Italian ryegrass row trial}

A trial was sown in early winter (2 July 1991) at Kaikohe, Northland, on an alluvial soil (Wairoro clay loam). This heavy clay is only subject to moderate summer-autumn soil moisture deficits and does not host black beetle, but in previous trials Argentine stem weevil has affected endophyte-free lines at this site. A total of 49 seed lines were sown in $1 \mathrm{~m}$ rows at $0.2 \mathrm{~g}$ of seed per row, with rows $30 \mathrm{~cm}$ apart and replicated three times in a randomised complete block design. The lines consisted of freshly harvested seed from 48 'Grasslands Moata' tetraploid Italian ryegrass half- sib families (BT648 - BT695) of which the maternal parents had been artificially infected with the AR5 (E187) N. lolii endophyte strain and a control Moata bulk (BT558) sown in duplicate. The control line was free of endophyte infection. AR5-infected plants produce the endophyte alkaloids peramine and ergovaline but not lolitrems.

The trial was visually assessed for plant growth on four occasions over the next 5 months, until early summer (6 December 1991). Growth was assessed for individual rows by scoring for relative herbage mass on a 1 (low) to 6 (high) scale. Immediately after each score was taken, the trial was mob grazed by sheep. Adequate $\mathrm{N}$ fertiliser as urea was applied regularly to maintain grass growth and $100 \mathrm{~kg} / \mathrm{ha}$ of $30 \%$ potassic superphosphate was applied annually.

\section{Italian ryegrass row and plot trials}

At Kerikeri, Northland (28 km from Kaikohe), plant performance of bulks of two diploid Italian ryegrass cultivars, 'Grasslands Status' and 'Corvette', harvested from plants that had been inoculated with the $N$. lolii strains AR1 and AR37, were compared with the same cultivars without endophyte or naturally infected with $N$. occultans at low or moderate rates. The AR1 strain produces peramine but not ergovaline or lolitrems. Neither AR37 nor $N$. occultans produces the aforementioned alkaloids but respectively produce epoxy-janthitrems and lolines. Although the Corvette lines evaluated in these trials originated from a single seed line of Corvette, the plants selected for $N$. occultans or no $N$. occultans, were morphologically different from those infected with AR1 and AR37. This became apparent during the seed production phase with the AR1 and AR37 plants having characteristics (e.g. degree of awning) that indicated less annual ryegrass parentage. The same plant morphological differences were not apparent for the three Status lines. Corvette and Status are more persistent than Moata but have lower cool season yields during the first year.

The soil at Kerikeri is an Okaihau gravely clay, a free-draining volcanic soil. Unlike the clay loam at Kaikohe, this soil is subject to severe moisture stress in summer and autumn and regular damage from black beetle, while Argentine stem weevil is also present. 
The first evaluation was in rows, similar to that described above for Moata, but with six replicates. Thirteen cultivars/lines were sown in late autumn 2002 (23 May), including four Corvette seed lines but none of the Status lines. The Corvette lines were either infected with AR1, AR37, or naturally infected with $N$. occultans at a low rate ("N. occultans-low") or at a moderate rate (" $N$. occultans-moderate") (Table 1). Rows were scored for relative herbage mass (1-10 scale, 1 = low mass) on 14 occasions over the next 20 months.

The second evaluation was a small plot trial sown in midautumn 2004 (8 April), which included both Corvette and Status (Cooper et al. 2006). The same $N$. occultans-infected Corvette lines were used but seed from the contributing plants was further screened to widen the gap between the levels of infection (Table 1). The Status "Nil" line had low rate of seeds infected with viable $N$. occultans ("N. occultans-low").

These six treatments, replicated four times in plots $(2.5 \mathrm{~m} \mathrm{x} 3$ $\mathrm{m}$ ), were measured over the following 2.5 years for dry matter yields when herbage reached $25-30 \mathrm{~cm}$ height. After each assessment, plots were mob grazed by sheep and $\mathrm{N}$ fertiliser applied. Herbicides were used to control other pasture species. Transect lines set diagonally across each plot were assessed for the occurrence of ryegrass plants in mid-autumn 2005 (19 April) (100 points per plot), approximately 1 year after sowing.

\section{Results and Discussion}

\section{Tetraploid Italian ryegrass row trial}

In the 1991 row trial at Kaikohe, the 49 seed lines had a wide range in plant performance $(\mathrm{P}<0.001)$, although the relative ranking among lines was consistent across the four dates of assessment (Date $\mathrm{x}$ Line interaction, $\mathrm{P}=0.99$ ). The families infected with endophyte were generally inferior to the endophyte-free control (Fig. 1).

Hume (1993, unpublished data) in a plot trial at Palmerston North found that infection of Moata with $N$. lolii could result in depressed winter yields for some plant genotype-endophyte strain combinations, compared with yields of endophyte-free isogenic plants. However, not all plant-strain combinations performed in the same way, with responses differing from yield depression, no yield differences, to increases in yield with endophyte infection relative to endophyte-free lines. The five endophyte strains used were in different plant genotypes, so no conclusion can be drawn as to differing yield effects being solely attributed to a particular strain. In Hume's study, it is not clear if AR5 was one of the five strains used, or an alternative, AR6. Long-term hybrid and perennial ryegrasses have not shown any yield depressions when infected with AR5 or AR6.

Unlike the Kaikohe result, in the trial reported by Hume (1993, unpublished data) there was an interaction with time of the year, with yields being higher for endophyte-infected treatments in the spring and summer. This is most likely a result of endophyte reducing the damage caused by Argentine stem weevil in springsummer, with up to $60 \%$ of endophyte-free tillers damaged by stem weevil larvae (Popay et al. 1995). This result also supports the findings of Piggot et al. (1988) and Prestidge (1991) for Italian ryegrasses. The presence of, and any damage caused by, Argentine stem weevil in 1991 at Kaikohe was not monitored. While one could speculate about the possible effects of Argentine stem weevil on the plant growth results at Kaikohe, the fact that AR5 infection in most Moata lines resulted in decreased winter yields, the main purpose for which short-lived Italian ryegrass is sown, does not support the case for inoculating such cultivars with this endophyte strain. However, the variation between infected families (Fig. 1) suggests that a useful AR5-infected Italian ryegrass could be developed to extend ryegrass persistence and production further into the spring and summer.

\section{Italian ryegrass row and plot trials}

In the row trial, significant differences occurred between the four Corvette lines $(\mathrm{P}=0.016)$ (Table 1$)$. The AR37 and $N$. occultansmoderate lines had significantly higher scores than the AR1 line $(\mathrm{P}=0.016)$ while $N$. occultans-low had an intermediate score. Differences between treatments were greatest from mid-summer of Year 1 onwards, but the Date x Line interaction did not reach the $5 \%$ significance level $(\mathrm{P}=0.062)$ (data not shown).

Similar effects occurred in the small plot trial (Table 1), with differences occurring from mid-autumn of Year 1 onwards. Again greater rates of infection with $N$. occultans in Corvette increased yields (on average by $36 \%$ ). Compared with the row trial, the AR1 line had improved performance being similar in yield to the AR37 and N. occultans-moderate lines. The Status lines infected with AR1 or AR 37 produced on average 15 to $52 \%$ more than the $N$. occultans-low line for the total trial period (Table 1) $(\mathrm{P}<0.05)$, with these differences ( 28 to $76 \%$ ) being greater from mid-autumn of Year 1 onwards (data not shown). In contrast to Corvette, Status AR37 was significantly better than Status AR1.

The yield differences that developed in plots from mid-autumn of Year 1, were closely associated with black beetle damage in late summer (Cooper et al. 2006) resulting in differences in plant frequencies in mid-autumn (Table 1). Protection against black beetle adult damage has been reported for infection of perennial ryegrass with AR37 (Ball et al. 1994) and to a lesser extent AR1 (Popay \& Jensen 2001). Effects of $N$. occultans infection on black beetle resistance have not been reported in the literature. While black beetle is not the only insect pest present at this site, its frequent occurrence and root damage when plants are under moderate to severe soil moisture stress makes it a significant constraint to plant persistence and productivity in ryegrass species and tall fescue (Cooper et al. 2002).

\section{Conclusions}

These trials have demonstrated the potential for certain strains of endophyte to enhance the productivity and persistence of short-lived Italian ryegrasses, particularly in regions subject to insect pressure and soil moisture deficit. Interactions between endophyte strain and cultivar, and possible detrimental effects on plant growth, mean that considerable effort may be required in a breeding programme to ensure a new $N$. lolii-infected Italian ryegrass cultivar offers agronomic advantages. Also agronomic advantages were in longer term persistence and production, and not the first year's cool season growth. This last attribute is the main reason farmers use such ryegrasses.

\section{ACKNOWLEDGEMENTS}

Anouck de Bonth, Michael Hickey and Wayne Simpson for endophyte testing.

\section{REFERENCES}

Ball, O.J.-P.; Christensen, M.J; Prestidge, R.A. 1994. Effect of selected isolates of Acremonium endophyte on adult black beetle (Heteronychus arator) feeding. pp. 227231. In: Proceedings of the 47th New Zealand Plant Protection Conference. 
Cooper, B.M.; Easton, H.S.; Hume, D.E.; Popay, A.J.; Baird, D.B. 2002. Improved performance in Northland of tall fescue with a novel endophyte. pp. 379-381. In: Proceedings of the 12th Australasian Plant Breeding Conference. Ed. McComb, J.A. Australasian Plant Breeding Association, Murdoch University, Murdoch, Australia.

Cooper, B.; Hume, D.; Panckhurst, K.; Popay, A.; Lyons, T. 2006. The role of perennial ryegrass endophyte in Italian ryegrass. pp. 526-530. In: Proceedings of the 13th Australasian Plant Breeding Conference. Ed. Mercer, C. New Zealand Grassland Association, Dunedin, New Zealand.

De Battista, J. 2005. Neotyphodium research and application in South America. pp. 65-71. In: Neotyphodium in CoolSeason Grasses. Eds. Roberts, C.A.; West, C.P.; Spiers, D.E. Blackwell Publishing, Ames, Iowa.

Forde, M.B.; Burgess, R.E.; Halligan, E.A.; Gardiner, S.E.; Latch, G.C.M. 1988. Varieties of Italian ryegrass in New Zealand. Proceedings of the New Zealand Grassland Association 49: 101-106.

Hume, D.E. 1993. Agronomic performance of New Zealand pastures: implications of Acremonium presence. pp. 31-38. In: Proceedings of the Second International Symposium on Acremonium/Grass Interactions: Plenary Papers. Eds. Hume, D.E.; Latch, G.C.M; Easton, H.S. AgResearch, Palmerston North, New Zealand.

Hume, D.E.; Christensen, M.J.; Hickey, M.J. 1993. Changes over time in the incidence of Acremonium endophyte in annual and short-lived hybrid ryegrass swards. pp. 210-213. In: Proceedings of the Second International Symposium on Acremonium/Grass Interactions. Eds. Hume, D.E.; Latch, G.C.M; Easton, H.S. AgResearch, Palmerston North, New Zealand.

Lancashire, J.A. 1982. Plant Growth in dairy pastures during the winter. pp. 347-358. In: Proceedings of the Conference on Dairy Farm Pastures. Eds. Macmillan K.L.; Taufa V.K. New
Zealand and Australian Societies of Animal Production.

Latch, G.C.M.; Christensen, M.J.; Hickson, R.E. 1988. Endophytes of annual and hybrid ryegrasses. New Zealand Journal of Agricultural Research 31: 57-63.

Piggot, G.J.; Morgan, H.M.; Bakker, R.J. 1988. Endophytes in Northland ecotypes of hybrid ryegrass. Proceedings of the 41st Weed and Pest Control Conference 41: 129-131.

Popay, A.J.; Baltus, J.G. 2001. Black beetle damage to perennial ryegrass infected with AR1 endophyte. Proceedings of the New Zealand Grassland Association 63: 267-271.

Popay, A.J; Hume, D.E.; Mainland, R.A.; Saunders, C.J. 1995. Field resistance to Argentine stem weevil Listronotus bonariensis in different ryegrass cultivars infected with an endophyte deficient in lolitrem B. New Zealand Journal of Agricultural Research 38: 519-528.

Popay, A.J.; Hume, D.E.; Davies, K.L.; Tapper, B.A. 2003. Interactions between endophyte (Neotyphodium spp.) and ploidy in hybrid and perennial ryegrass cultivars and their effects on Argentine stem weevil (Listronotus bonariensis). New Zealand Journal of Agricultural Research 46: 311-319.

Prestidge, R.A. 1991. Susceptibility of Italian ryegrasses (Lolium multiflorum Lam.) to Argentine stem weevil (Listronotus bonariensis (Kuschel)) feeding and oviposition. New Zealand Journal of Agricultural Research 34: 119-125.

Stewart, A.V. 1985. Perennial ryegrass seedling resistance to Argentine stem weevil. New Zealand Journal of Agricultural Research 28: 403-407.

Stewart, A.V. 1987. Plant-breeding aspects of ryegrass (Lolium spp.) infected with endophytic fungus. Ph.D. Lincoln College, Canterbury, New Zealand.

Sugawara, K.; Inoue, T.; Yamashita, M.; Ohkubo, H. 2006. Distribution of the endophytic fungus, Neotyphodium occultans in naturalized Italian ryegrass in western Japan and its production of bioactive alkaloids known to repel insect pests. Grassland Science 52: 147-154. 